\title{
Steel Slag as an Aggregate Replacement in Malaysian Hot Mix Asphalt
}

\section{Mohd Rosli Hainin, ${ }^{1}$ Nur Izzi Md. Yusoff,, ${ }^{2}$ Mohd Fahmi Mohammad Sabri, ${ }^{1}$ Mohd Azizi Abdul Aziz, ${ }^{1}$ Mohd Anwar Sahul Hameed, ${ }^{1}$ and Wasid Farooq Reshi ${ }^{1}$}

\author{
${ }^{1}$ Department of Geotechnics and Transportation, Faculty of Civil Engineering, Universiti Teknologi Malaysia, \\ 81310 Skudai, Johor, Malaysia \\ ${ }^{2}$ Department of Civil and Structural Engineering, Faculty of Engineering and Built Environment, \\ Universiti Kebangsaan Malaysia, 43600 Bangi, Selangor, Malaysia
}

Correspondence should be addressed to Nur Izzi Md. Yusoff, izzi@eng.ukm.my

Received 12 July 2012; Accepted 2 August 2012

Academic Editors: D. Huang and I. G. Raftoyiannis

Copyright (๑) 2012 Mohd Rosli Hainin et al. This is an open access article distributed under the Creative Commons Attribution License, which permits unrestricted use, distribution, and reproduction in any medium, provided the original work is properly cited.

\begin{abstract}
As natural aggregate sources are becoming depleted due to high demand in road construction and the amount of disposed waste material keeps increasing, researchers are exploring the use of alternative materials which could preserve natural sources and save the environment. In this study, steel slag was used as an aggregate replacement in conventional dense graded asphalt mixes (ACW14 and ACB28). Steel slag was selected due to its characteristics, which are almost similar to conventional aggregates, and the fact that it is easily obtainable as a by-product of the steel industry. The same gradations of mixtures were produced using normal crushed aggregate as control samples. The Marshall mix design system was used for sample preparation in accordance with Malaysian specifications. Samples of asphaltic concrete were subjected to the resilient modulus test, creep test and rutting test. Samples made from steel slag show significantly better results than conventional aggregate. Therefore, utilization of steel slag will reduce land fill, save natural resources and improve the strength of pavement to sustain a higher volume of vehicles. This will shift the gear in sustainable pavement construction, which is most desirable in today's energy deficient world.
\end{abstract}

\section{Introduction}

The development of the highway construction industry is increasing rapidly. Consequently, the aggregate resources in Malaysia are becoming depleted, and the land is being sacrificed to obtain raw materials. Thus, it is necessary to find a recycled material that can replace aggregates in highway construction. Much research has been done to improve and upgrade the materials used for preparing hot-mix asphalt (HMA). The utilization of waste material as a replacement for aggregates in the production of HMA could have many benefits to mankind. Waste materials can be categorized broadly as follows: industrial waste (e.g., cellulose waste, wood lignins, slags, bottom ash, and fly ash), municipal or domestic waste (e.g., incinerator residue, scrap rubber, waste glass, and roofing shingles) and mining waste (e.g., coal mine refuse) [1].
Steel-slag is a byproduct of the steel industry, and is reported to exhibit great potential as a replacement for natural aggregates in road construction. Steel-slag is a waste material that can be recycled as a road construction material. Steel-slag aggregates have been reported to retain heat considerably longer than natural aggregates. The heat retention characteristics of steel-slag aggregates can be advantageous for HMA construction, as less gas (energy) is used during the execution of asphaltic concrete works. Based on high frictional and abrasion resistance, steel-slag is used widely in industrial roads, intersections, and parking areas where high wear resistance is required. It can be used as an aggregate replacement for HMA, road base, and subbase. Steel-slag, a dark colored material, is hard, dense, and abrasion resistant. It contains a significant amount of free iron, giving the material high density and hardness [1]. In addition, steel-slag is chemically stable and shows excellent binding properties 
TABLE 1: Aggregate testing results.

\begin{tabular}{|c|c|c|c|}
\hline Testing & Procedures & Results & Specification JKR/SPJ/1988 \\
\hline Aggregate crushing value & BS 812 Part 110: 1990 & $23 \%$ & $<30 \%$ \\
\hline Los angeles abrasion & ASTM C 131-1981 & $24 \%$ & $<30 \%$ \\
\hline Aggregate impact value & BS 812: Part 112: 1990 & $23 \%$ & - \\
\hline Flakiness (Coarse, 28 mm) & BS812: Section 105.1: 1989 & $3 \%$ & $<30 \%$ \\
\hline Flakiness (Coarse, 20 mm) & BS812: Section 105.1: 1989 & $2 \%$ & $<30 \%$ \\
\hline Flakiness (Coarse, 14 mm) & BS812: Section 105.1: 1989 & $3 \%$ & $<30 \%$ \\
\hline Soundness & AASHTO: T 104-86 & $2.07 \%$ & $<18 \%$ \\
\hline Polished stone value & BS 812: Part 14: 1989 & 54 & $>40$ \\
\hline Water absorption (ACW14) & \multirow{2}{*}{ BS 812: Part 2: 1975} & $6.92 \%$ & \multirow{2}{*}{$<2 \%$} \\
\hline Water absorption (ACB28) & & $5.46 \%$ & \\
\hline Stripping & AASHTO: T 182 & $>95 \%$ & $>95 \%$ \\
\hline
\end{tabular}

with bitumen, has a low flakiness index, good mechanical properties, and good antiskid resistance [2].

Work done by various researchers has found that the addition of steel slag in HMA enhances the performance characteristics of pavement [3-5]. Since steel slag is rough, the material improves the skid resistance of pavement. Also, because of the high specific gravity and angular, interlocking features of crushed steel slag, the resulting HMA concrete is more stable and resistant to rutting [5-7]. Recently, the use of steel slag with stone mastic asphalt (SMA) has been further investigated [8]. It has been observed that the use of steel slag in SMA mixtures enhances resistance to cracking at low temperatures. In addition, in service, SMA mixtures also present excellent performance in roughness and the British Pendulum Number (BPN) coefficent of surface [8]. Concerns over potential expansion of steel slag aggregates have generally not materialised as the asphalt film coating the aggregate particles limit ingress and therefore expansion [9].

Steel-slag aggregates have been used successfully in asphalt-surfacing mixtures as well as base layers in Europe, Canada, Australia and as well as in the USA [10-15]. Very limited work, however, has been done in Malaysia regarding the performance of steel-slag mixtures. Therefore, this study was conducted to determine the feasibility of using steelslag aggregate in asphaltic concrete wearing 14 (ACW14) and asphaltic concrete binder 28 (ACB28) asphalt mixes. The performance of ACW14- and ACB28-steel-slag mixtures will be evaluated in terms of the resilient modulus, rutting, and creep deformations. All the parameters were obtained from tests performed at the Highway and Transportation Laboratory, University Teknologi Malaysia. In this study, $80 / 100$ penetration grade bitumen was used and all the specifications were referred to the Malaysian Standard (SPJ/JKR/ 1988). Steel-slag aggregates were obtained from Purata Keuntungan Sdn. Bhd, which is located at Pasir Gudang, and the virgin aggregates were obtained from Malaysian Rock Product (MRP) Quarry, which is situated at Ulu Choh, Pulai.

As we know, the production of steel-slag, which is a byproduct of the steel industry, is very high, and the demand for areas in which to dispose this material is also increasing. Eventually, it will become increasingly costly to the steel industry, as the price of land is increasing, especially in urban and development areas. So, using steel-slag as an aggregate replacement in highway construction is a step towards green technology and sustainability. This alternative will help to save our hills from being exploited for raw materials, such as granite, for highway construction.

\section{Experimental Design}

The experimental work involved testing both steel-slag aggregates and conventional aggregates. The steel-slag aggregates were subjected to several tests before the process of sample production was conducted. The properties of steelslag aggregates are shown in Table 1.

2.1. Resilient Modulus Test. The resilient modulus is an important parameter to determine the performance of pavement and to analyze pavement response to traffic loading. Although it was once believed that stiffer pavements had greater resistance to permanent deformation, it has since been concluded that the resilient modulus at low temperatures is somewhat related to cracking, as stiffer mixes (higher resilient modulus) at low temperatures tend to crack sooner than more flexible mixtures (lower resilient modulus) [16]. In this study, the resilient modulus at $25^{\circ} \mathrm{C}$ and $40^{\circ} \mathrm{C}$ was obtained for the mixture. The procedures of this test are based on ASTM D 4123-82.

2.2. Rutting Test. Rutting is a longitudinal surface depression in the wheel paths [17]. Rutting is sometimes called grooving or channelling. Rutting displaces the asphalt mixture in the wheel path, creating a channel. A major type of asphaltic concrete pavement failure is rutting, which is manifested at the surface [18]. The rutting potential of various types of mixes were measured with accumulated permanent deformation at an interval of 25 load cycles to 5000 load repetitions or $15 \mathrm{~mm}$ rut depth. The procedures of this test are based on ASTM D 3203-91.

2.3. Creep Test. This test was conducted to determine permanent deformation of asphalt mixtures. The static load is measured as a function of time, while the mixture dimensions and test conditions are standardized. The duration of the 
TABLE 2: Optimum bitumen content (OBC).

\begin{tabular}{cccc}
\hline \multicolumn{2}{c}{ Type of mix } & OBC (\%) & SPJ/JKR/1988 \\
\hline \multirow{2}{*}{ ACW14 } & Steel slag & 6.7 & $5-7 \%$ \\
& Control & 5.0 & \\
\multirow{2}{*}{ ACB28 } & Steel slag & 5.7 & $4-6 \%$ \\
& Control & 4.3 & \\
\hline
\end{tabular}

TABLE 3: Marshall results and specifications for ACW14.

\begin{tabular}{lccccc}
\hline \multirow{2}{*}{ Parameter } & \multirow{2}{*}{ Specification } & \multicolumn{4}{c}{ Value at OBC } \\
& & Steel slag & Control sample \\
\hline VFB & $75-85$ & 78 & Pass & 79.5 & Pass \\
VTM & $3-5$ & 5 & Pass & 3.4 & Pass \\
Stability $(\mathrm{kg})$ & $>500$ & 2200 & Pass & 1339.0 & Pass \\
Flow $(\mathrm{mm})$ & $>2.0$ & 4.3 & Pass & 2.2 & Pass \\
Stiffness $(\mathrm{kg} / \mathrm{mm})$ & $>250$ & 512 & Pass & 623.0 & Pass \\
\hline
\end{tabular}

TABLE 4: Marshall results and specifications for ACB28.

\begin{tabular}{lccccc}
\hline \multirow{2}{*}{ Parameter } & \multirow{2}{*}{ Specification } & \multicolumn{4}{c}{ Value at OBC } \\
& & \multicolumn{2}{c}{ Steel slag } & \multicolumn{3}{c}{ Control sample } \\
\hline VFB & $65-80$ & 70 & Pass & 72.6 & Pass \\
VTM & $3-7$ & 6.3 & Pass & 3.97 & Pass \\
Stability $(\mathrm{kg})$ & $>450$ & 2300 & Pass & 1662 & Pass \\
Flow $(\mathrm{mm})$ & $>2.0$ & 4.7 & Pass & 4.53 & Pass \\
Stiffness $(\mathrm{kg} / \mathrm{mm})$ & $>225$ & 489 & Pass & 367 & Pass \\
\hline
\end{tabular}

test was 3600 seconds loading and 600 seconds unloading. A static loading stress of $200 \mathrm{kPa}$ was applied at a temperature of $40^{\circ} \mathrm{C}$.

\section{Results and Discussion}

3.1. Marshall Test. The optimum bitumen content (OBC) is the most important criterion in preparing the samples. This is because any error in obtaining OBC will definitely influence the outcome. The $\mathrm{OBC}$ values for the mixtures were as shown in Table 2. Detailed data of the tests conducted in order to obtain the optimum bitumen content of both ACW14 and ACB28 are described in Tables 3 and 4, respectively. Based on the above results, it is clear that the selected optimum bitumen content for each grading met the requirements of JKR/SPJ/1988. This is very important, since the performance of the samples will be affected greatly by the $\mathrm{OBC}$ when tested for rutting, resilient modulus, and permanent deformation.

3.2. Resilient Modulus. Figure 1 clearly shows the resilient modulus for asphaltic concrete wearing (ACW14). Based on these results, the resilient modulus at $25^{\circ} \mathrm{C}$ yields a better result compared to $40^{\circ} \mathrm{C}$. The results also show that the steel-slag mixture yields a higher resilient modulus value compared to the control mixture at both temperatures. At $25^{\circ} \mathrm{C}$, the resilient modulus is $4436.15 \mathrm{MPa}$ for the steel-slag mix and 1976.85 MPa for the conventional mixture; while

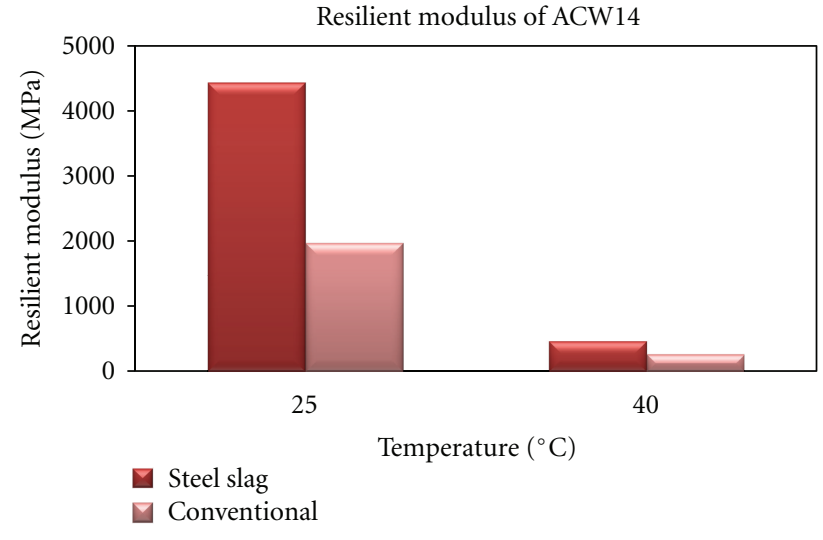

Figure 1: Resilient modulus for ACW14.

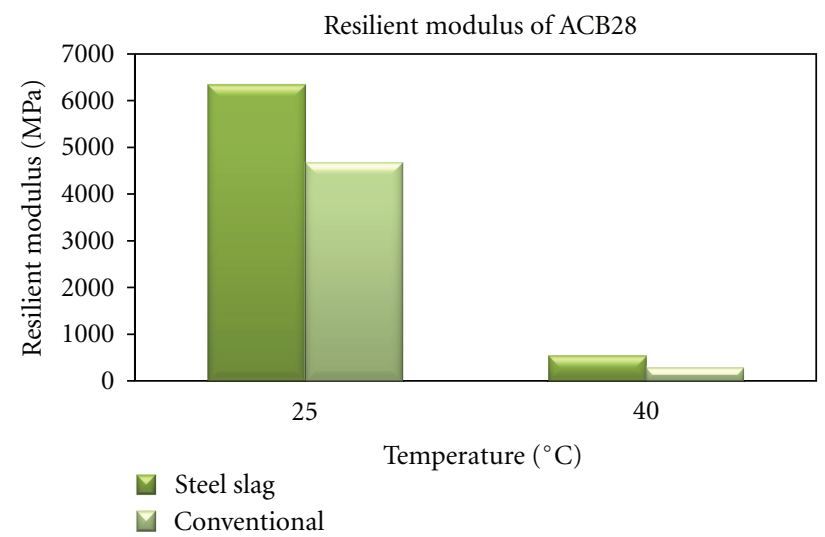

Figure 2: Resilient modulus for ACB28.

at $40^{\circ} \mathrm{C}$, the resilient modulus is $471.35 \mathrm{MPa}$ for the steelslag mix and $268.15 \mathrm{MPa}$ for the conventional mixture. The results indicate that when steel-slag was used, the resilient modulus obtained was almost twice that of conventional aggregate.

The resilient modulus for asphaltic concrete binder (ACB28) is presented in Figure 2. Tests carried out at $25^{\circ} \mathrm{C}$ and $40^{\circ} \mathrm{C}$ resulted in similar trends with ACW14, whereas the steel-slag mixture shows a greater resilient modulus compared to the conventional mixture at both temperatures. As depicted in Figure 2, at $25^{\circ} \mathrm{C}$, the resilient modulus for the steel-slag-aggregate-based mixture is greater than the conventional-aggregate-based mixture, with values of 6353.15 MPa and 4674.85 MPa respectively. The difference between these two mixtures is about $26 \%$. This pattern is also similar for the resilient modulus tested at $40^{\circ} \mathrm{C}$, where the value for the mixture containing steel-slag aggregate was recorded as $542.65 \mathrm{MPa}$, and $291.35 \mathrm{MPa}$ for the conventional aggregate-based mixture, about a $46 \%$ difference.

3.3. Rutting. Figure 3 shows the results for the rutting potential of asphaltic concrete (ACW14) using steel-slag and conventional aggregates. The results show that the steelslag aggregate mix presented a lower rutting depth in comparison to the conventional mixture. This can be clearly 


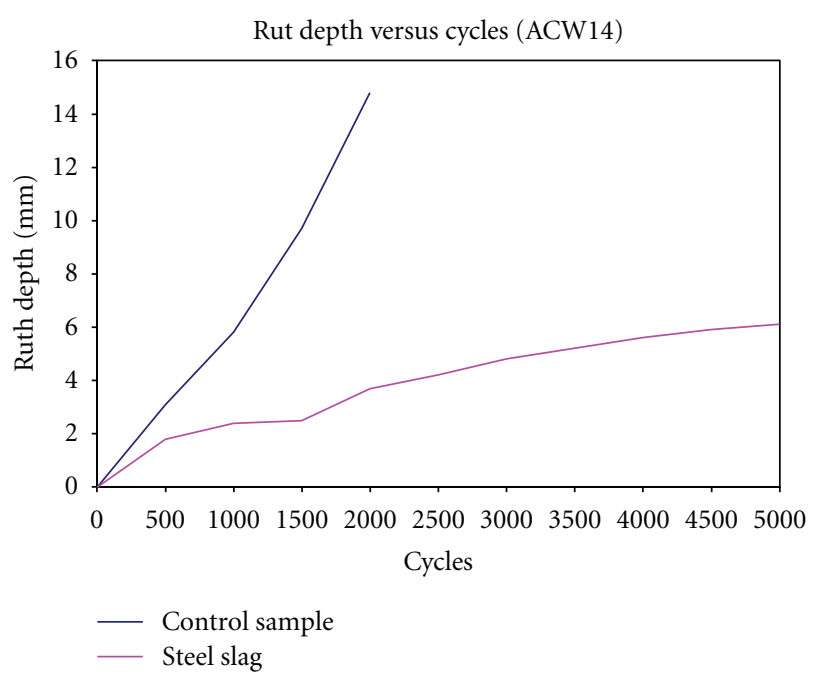

Figure 3: Rutting depth for ACW14.

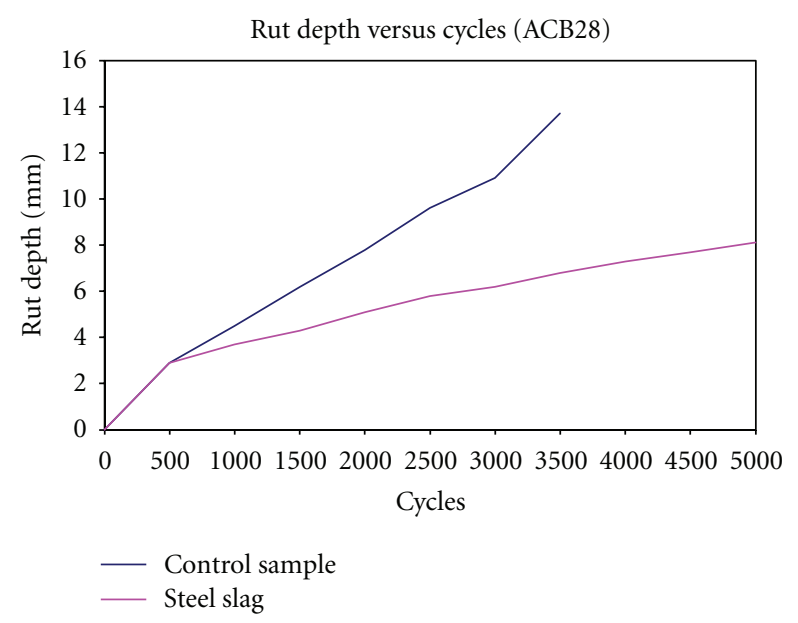

FIgURE 4: Rutting depth for ACB28.

observed in Figure 3. Steel-slag can resist more rutting (6.1 mm after 5000 cycles), while rutting on the conventional mixture was $15 \mathrm{~mm}$ after only 2019 cycles. The steel-slag mixture exhibited more resistance to permanent deformation compared to the conventional mixture in the wheel tracking test.

The rutting potential of asphaltic concrete binder (ACB28) with steel-slag and a conventional mixture is presented in Figure 4. The results follow a similar trend as for ACW14, where the steel-slag mixture has a lower rutting depth than the conventional aggregate mixture. The rutting depth of the steel-slag aggregate mixture was $8.1 \mathrm{~mm}$ after 5000 cycles, while for the conventional mixture it was $15 \mathrm{~mm}$ after just 3681 cycles. The lower rutting depth of the steel-slag mixture can be explained by the fact that steel-slag interlocks well within the mixture, which is undeniably essential for deformation resistance. Thus, for ACB28, using steel-slag as an aggregate replacement could cater for a higher volume of traffic due to its greater adhesion ability.

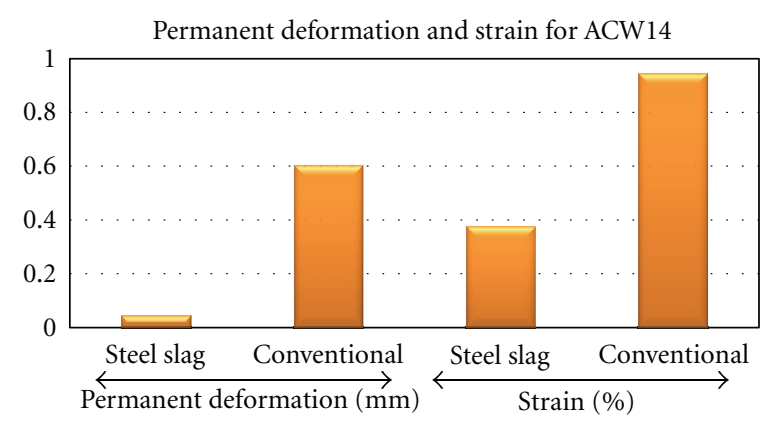

Figure 5: Creep test for ACW14.

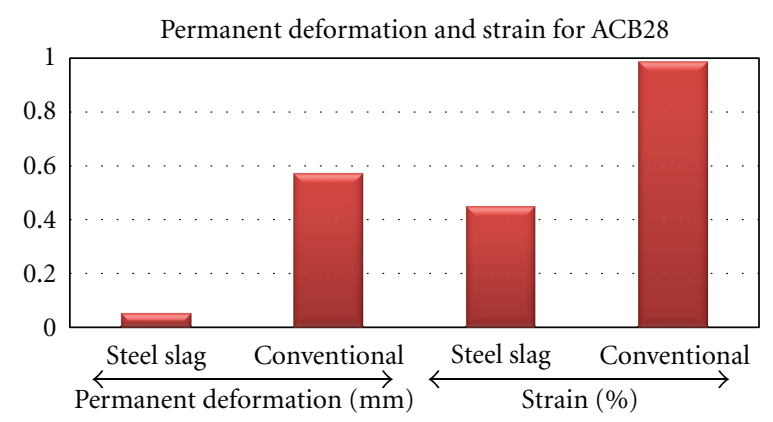

Figure 6: Creep test for ACB28.

3.4. Creep Test. Figure 5 shows the results for the permanent deformation and strain of asphaltic concrete wearing (ACW14). From the results it is clear that permanent deformation and strain for the steel-slag mixture is lower than for the conventional mixture. Permanent deformation for the steel-slag mixture is $0.044 \mathrm{~mm}$, while for the conventional mixture it is $0.605 \mathrm{~mm}$. The strain for the steel-slag mixture is $0.377 \%$ and $0.946 \%$ for the conventional mixture. The steelslag mixture has good behaviour in terms of interlocking and adhesion. Thus, the steel-slag mixture proves that it can resist greater deformation and can last longer when compared to the conventional mixture.

The permanent deformation and strain for asphaltic concrete binder (ACB28) is presented in Figure 6. The result exhibits a similar trend to that of ACW14, in that the steel-slag mixture has smaller deformation and strain possibilities than the conventional mixture in terms of rutting depth. Permanent deformation for the steel-slag mixture is $0.053 \mathrm{~mm}$, whereas it is $0.574 \mathrm{~mm}$ for the conventional mixture. The strain value for the steel-slag and conventional mixture is $0.451 \%$ and $0.897 \%$, respectively. Therefore, it can be concluded that asphaltic concrete binder using steel-slag has a higher resistance to deformation and could therefore cater for higher traffic loadings.

\section{Conclusions}

The conclusions that can be drawn from this research are as follows:

(i) In terms of optimum bitumen content, the steel-slag mixture has a higher value than the conventional 
mixture. This is due to the higher degree of porosity possessed by steel-slag aggregates.

(ii) The resilient modulus result indicates that the steelslag mixture has a higher value compared to the conventional aggregate mixture. Furthermore, temperature also influences the resilient modulus result.

(iii) In terms of rutting, the mixture prepared with steel-slag has greater cohesive strength compared to the conventional mixture. Thus, asphaltic concrete wearing using steel-slag has a higher load resistance than the conventional mixture.

(iv) For the creep test, steel-slag shows lower permanent deformation and strain than conventional aggregates. The reason behind this result can be attributed to the interlocking properties of steel-slag that impart greater adhesion to the mixture.

The results of this study suggest that utilization of steelslag aggregate can benefit the environment and at the same time reduce the amount of granite application in highway construction. With its excellent results in terms of the resilient modulus and lower rutting potential, it is recommended that steel-slag be used as an aggregate replacement for sustainable development in highway construction.

\section{References}

[1] P. Ahmedzade and B. Sengoz, "Evaluation of steel slag coarse aggregate in hot mix asphalt concrete," Journal of Hazardous Materials, vol. 165, no. 1-3, pp. 300-305, 2009.

[2] S. L. See, "Steel slag used in the construction industry," Nat Steel Chemicals Ltd., 1998.

[3] A. R. Lee, Blast Furnace and Steel Slag: Production, Properties and Uses, Edward Arnold, London, UK, 1974.

[4] U. Bagampadde, H. I. Al-Abdul Wahhab, and S. A. Aiban, "Optimization of steel slag aggregates for bituminous mixes in Saudi Arabia," Journal of Materials in Civil Engineering, vol. 11, no. 1, pp. 30-35, 1999.

[5] A. S. Noureldin and R. S. McDaniel, "Evaluation of surface mixtures of steel slag and asphalt," in Transportation Research Record 1296, pp. 133-139, National Academy Press, 1990.

[6] T. L. Ramirez, "Steel slag aggregates in bituminous mixtures," Research Project No. 74012, 1992.

[7] B. Lemass, "Slag solutions for heavy duty road pavements," in Proceedings of the 16th Australian Road Research Board Conference, Part 2 (ARRB '92), pp. 105-118, November 1992.

[8] S. Wu, Y. Xue, Q. Ye, and Y. Chen, "Utilization of steel slag as aggregates for stone mastic asphalt (SMA) mixtures," Building and Environment, vol. 42, no. 7, pp. 2580-2585, 2007.

[9] G. D. Airey, A. C. Collop, N. H. Thom, S. E. Zoroob, and A. Shiratori, "Laboratory evaluation of secondary aggregates in bituminous mixtures," Journal of the Association of Asphalt Paving Technologists, vol. 73, pp. 731-770, 2004.

[10] J. J. Emery, "Slag utilization in pavement construction," in Extending Aggregate Resources, pp. 95-118, ASTM STP 774, American Society for Testing and Materials, 1982.

[11] A. R. Lee, Blast Furnace and Steel Slag: Production, Properties and Uses, Halsted Press, New York, NY, USA, 1975.

[12] A. S. Noureldin and R. S. McDaniel, "Performance evaluation of steel slag furnace slag- natural sand asphalt surface mixtures," Journal of the Association of Asphalt Paving Technologists, vol. 68, pp. 276-303, 1990.
[13] D. A. Anderson and J. J. Henry, " Synthetic aggregates for skid resistance surface courses," Transportation Research Record, no. 712, pp. 61-68, 1979.

[14] J. Ryell, J. T. Corkill, and G. R. Musgrove, "Skid resistance of bituminous pavement test sections: Toronto by-pass project," Transportation Research Record, no. 712, pp. 51-61, 1979.

[15] P. S. Kandhal and G. L. Hoffman, "Evaluation of steel slag fine aggregate in hot-mix asphalt mixtures," Transportation Research Record, no. 1583, pp. 28-36, 1997.

[16] S. Michael, A. C. Bruce, and D. Andrew, "Investigation of recycled martial asphalt pavement (RAP) mixtures," Minnesota Department of Transportation, USA, 2002.

[17] P. Lavin, Asphalt Pavements: A Practical Guide to Design, Production and Maintenance for Engineers and Architects, Taylor and Francis Group, New York, NY, USA, 2003.

[18] R. A. Jimenez, "ASPHALT: mixture design method to minimize rutting," Transportation Research Record, no. 1417, pp. 109-116, 1993. 

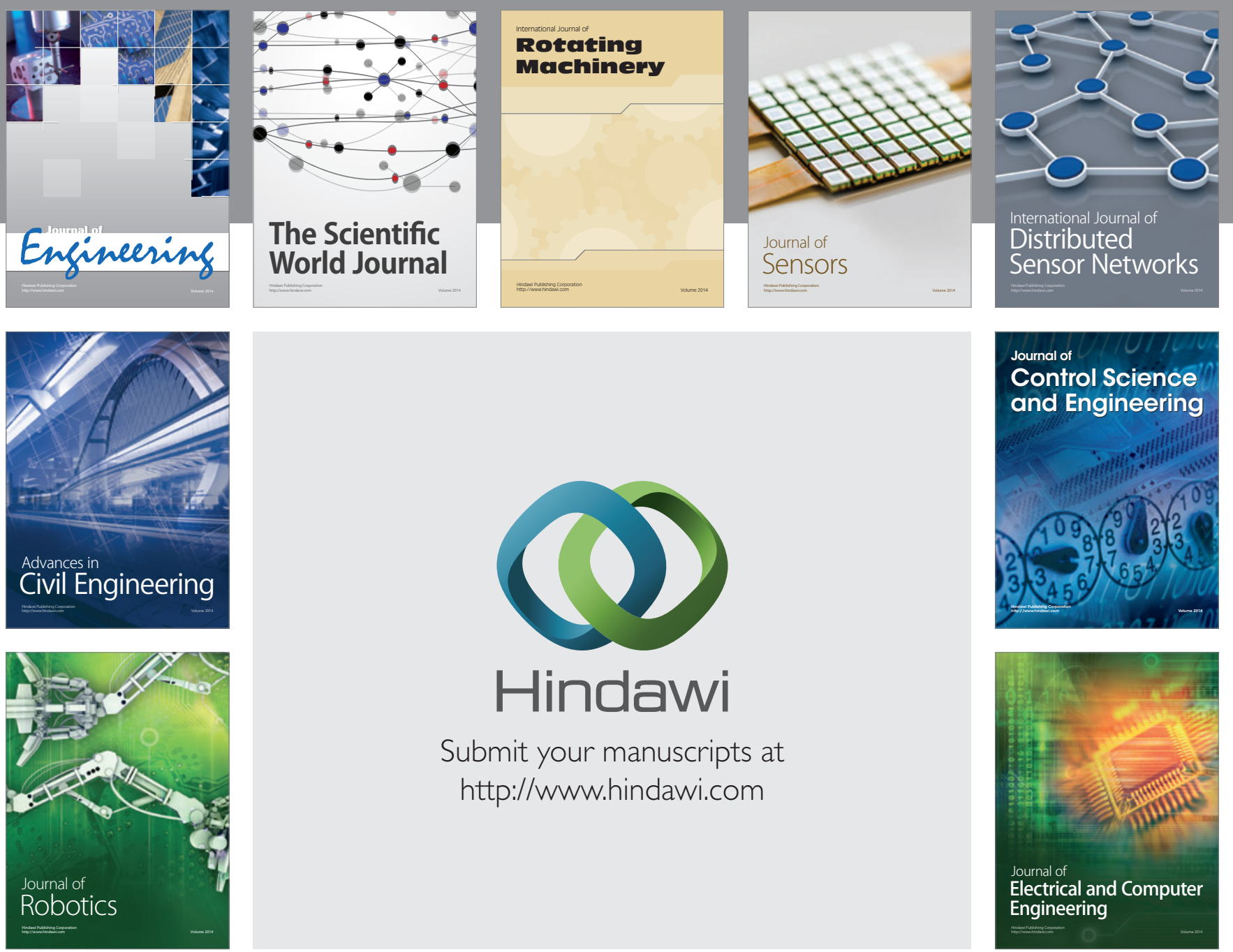

Submit your manuscripts at

http://www.hindawi.com
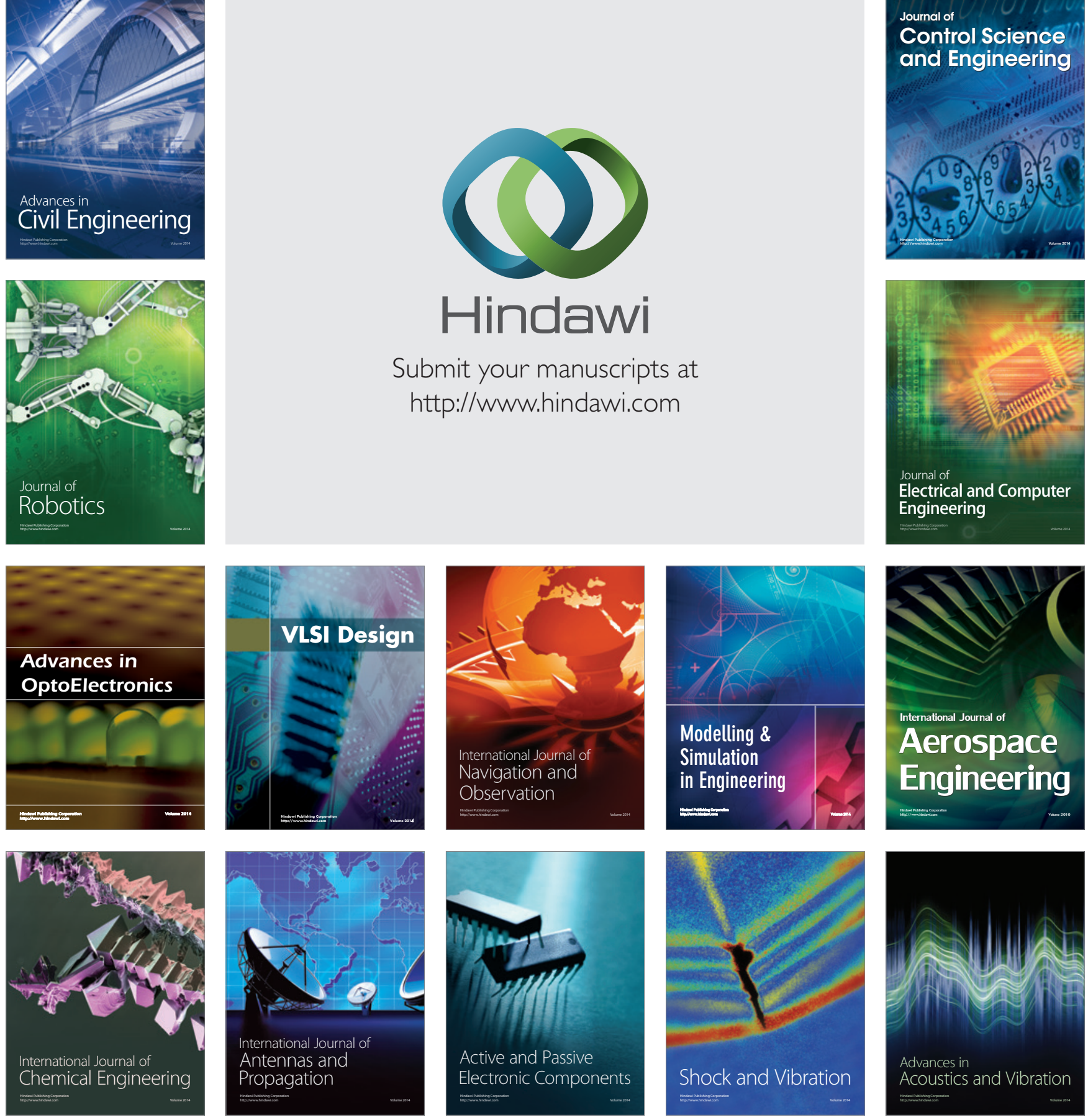